\title{
LA REFORMA DIECIOCHESCA DEL CONVENTO HOSPITAL DE SAN JUAN DE DIOS DE EL PUERTO DE SANTA MARÍA
}

\author{
José Ramón Barros Caneda \\ Universidad de Cádiz
}

\section{RESUMEN}

El Puerto de Santa María en la provincia de Cádiz vivió, al igual que su entorno, un importante auge constructivo durante el siglo XVIII. Dicho desarrollo incidió en la creación de nuevos edificios y en la transformación o ampliación de otros. El incremento de las necesidades asistenciales y la presencia desde el siglo anterior de la Orden de San Juan de Dios en la ciudad, condujo a la imprescindible ampliación del primitivo Hospital de la Misericordia dotándolo de nuevas dependencias que terminaron por configurar este inmueble situado en la calle Luna. La aparición de Francisco Gainzaráin, maestro cantero de procedencia sevillana, y la influencia de las yeserías cordobesas en la decoración de la bóveda de la escalera, le prestan un especial interés a esta obra de reforma ejecutada, inicialmente, entre 1734 y 1735.

Palabras clave: El Puerto de Santa María. Convento hospital de San Juan de Dios. Arquitectura conventual. Francisco Gainzaráin. Siglo XVIII.

\section{ABSTRACT}

Like many others cities, El Puerto de Santa María in the province of Cádiz, was developed, during the 18th century, a time of intensive growth in the building industry. This situation generated new buildings and favored the improvement of the existing ones. The growth of medical care and the presence of the San Juan de Dios Order, led to an expansion of the old Misericordia Hospital with new additions like a cloister, staircase and cementery. The presence of Francisco Gainzaráin, a Sevillian stonemason, and the influence of Cordoba's ornamentations make this construction a huge attraction.

Key words: El Puerto de Santa María. San Juan de Dios Hospital. Religius arquitecture. Francisco Gainzaráin. 18th century. 
Ubicada en el Hospital de Santa Lucía, la presencia de la Orden de San Juan de Dios en El Puerto de Santa María se remonta a 1587, aunque hasta 1605 no se realizarán los primeros contactos de la Orden con el Hospital de la Misericordia. Pese a esta fecha inicial, la fundación se llevó a cabo en 1660, mientras que la ocupación del inmueble se hizo efectiva el 31 de marzo del año siguiente ${ }^{1}$. El origen de este cambio fue la decisión del Duque de Medinaceli de expulsar a la Hermandad de la Misericordia del edificio y ceder su administración y gestión a la Orden de San Juan de Dios. Bajo los nuevos ocupantes, el hospital continuó su funcionamiento y crecimiento gracias a las ayudas iniciales del Cabildo Municipal y a las aportaciones y rentas producidas por las capillas de la iglesia. De estos primeros momentos se sabe que la obra del coro de la iglesia fue costeada por el cabildo portuense en 1638 y que en 1653 solicitaron de nuevo ayuda al cabildo para continuar las obras de la iglesia que al parecer se ejecutan en el período comprendido entre ese año y $1671^{2}$. La venta de una capilla a Juan de Salazar en 1676 permite corroborar esta noticia. En el texto del protocolo se describe la capilla como la "primera del lado derecho del evangelio que mira y hace esquina al crucero y altar de $\mathrm{N}^{\circ}$. Padre San Juan de Dios" ${ }^{\text {"3 }}$ Una nueva venta de capilla en esta ocasión a Fernando Francisco Philipo en 1709 permite constatar, con respecto a la anterior, una diferencia esencial en la configuración del inmueble. Ahora se le concede al citado Philipo, por la ayuda a la fabrica y a la labor curativa de los enfermos, "entierro en la capilla y altar de $\mathrm{N}^{\circ}$. Padre San Juan de Dios que es colateral al lado del ebangelio en el crucero de la capilla mayor de la iglesia inmediato a la puerta que sale al claustro"4. En este año, 1709, como vemos, ya aparece citado el claustro como pieza constitutiva del convento y en la ubicación actual, si bien se tiene constancia de que unos años antes, en 1706, el prior pide al Cabildo Municipal que le conceda carretadas de cantillo de las canteras para iniciar las obras del claustro y reparaciones de la iglesia ${ }^{5}$. Sobre esta configuración inicial del edificio, a la que habría que añadir salas de enfermería y dependencias hospitalarias ${ }^{6}$, se llevó a cabo una gran modificación en el segundo tercio del siglo XVIII. Para el desarrollo de la vida del convento y hospital se recibieron numerosas ayudas procedentes de diferentes ámbitos sociales. En este sentido, siguen siendo numerosas las ofrecidas por el municipio el cual, según González Beltrán, mantenía muy buenas relaciones con el hospital, apoyándolo con numerosos donativos y con el ofrecimiento de servicios públicos de manera gratuita y licencias para celebrar actos benéficos ${ }^{7}$.

Pero no sólo el Cabildo portuense financiaba con ayudas al hospital. Las fuentes de ingresos también procedían de numerosos particulares que donaban rentas y bienes, destacando además los negocios y rentas de que disponía la propia institución. En los protocolos notariales de este período se localizan algunos ejemplos de tributos, obligaciones, redenciones de censos, etc. que nos indican las formas de financiación ${ }^{8}$, y que complementan a las ofrecidas por Iglesias Rodríguez para la segunda mitad del siglo XVIII ${ }^{9}$. A éstas se añadirían aportaciones de personajes relevantes de la nobleza y

GONZÁLEZ LUQUE, Francisco: Antiguo Hospital de la Misericordia y San Juan de Dios. En Pliegos de la Academia, $\mathrm{n}^{\circ} 24$ y 25 , Julio-octubre 1997, págs. 6-11.

Ibidem.

ARCHIVO HISTÓRICO PROVINCIAL DE CÁDIZ (en adelante A.H.P.C.). Protocolos de El Puerto de Santa María. Leg. 315. 1676. $2^{\circ}$ cuaderno, s/f. En el texto del protocolo se menciona la construcción de un retablo nuevo, sin especificar en que zona de la iglesia.

${ }_{4}$ Tomado de SANCHO DE SOPRANIS, Hipólito: Historia del Puerto de Santa María. Desde su incorporación a los dominios cristianos en 1295 hasta el año mil ochocientos. Ensayo de una síntesis. Edición a cargo de Francisco Javier Fornell Fernández. Cádiz, 2006. Citado por GONZÁLEZ LUQUE, Francisco: Ibídem. El documento de cesión del enterramiento se halla en A.H.P.C. Protocolos de El Puerto de Santa María. Leg. 437. Escribanía 3ª 1709. Donazión del Convento de San Juan de Dios a Fdo. Fco. Philipo, fol. 276 y ss.

GONZÁLEZ LUQUE, Francisco. Op. Cit., pág. 7. La referencia documental, no citada, de estos datos es ARCHIVO MUNICIPAL DE EL PUERTO DE SANTA MARIA ( en adelante A.M.P.S.M.). Actas Capitulares, 1706, fol. 135v.

6 En el año 1700, Baptistina Gallo lega 75 pesos de plata "para ayuda de la obra de la enfermeria que esta fabricando". A.H.P.C. Protocolos de El Puerto de Santa María. Leg. 399. 1700, fol. 327.

Al respecto véase GONZÁLEZ BELTRÁN, Jesús Manuel: El cabildo municipal de El Puerto de Santa María (1725-1734). Cádiz, 1989, pág. 192-194.

$8 \quad \mathrm{Al}$ respecto véase A.H.P.C. Protocolos de El Puerto de Santa María. Leg. 401. Escribanía 3ª 1701. Tributo de Antón Blas al convento Hospital de San Juan de Dios, fol. 5 y ss. Ídem. Leg. 429. Escribanía 6a. 1706. Obligación de Mariana Bravo de los Olivos al Convento Hospital de la Misericordia, fol. 345. Ídem, Leg. 512. Escribanía 4a. 1726. Redención del convento de San Francisco al de San Juan de Dios, fol. 110.

9 IGLESIAS RODRÍGUEZ, Juan José: Una ciudad mercantil del siglo XVIII. El Puerto de Santa María. Cádiz, 1991, págs. 566-568. 
burguesía comercial portuense tales como el Duque de Medinaceli, la familia Rodríguez Cortés, los Vizarrón Araníbar y los ya citados Philippo.

Estas donaciones permitieron la progresiva ampliación de la institución hospitalaria, lo que demuestra la relevancia que iba adquiriendo la labor asistencial. De hecho, aparecen algunas noticias sobre ampliaciones como la realizada en 1726 para la construcción de una sala nueva ${ }^{10}$. Pero entre los donantes ya citados destaca uno de gran importancia que constituyó el soporte económico de la importante reforma efectuada en el inmueble durante los años 1734 y 1735.

En 1732, Andrés de la Azuela, lega en su testamento una importante cantidad de dinero al Hospital de San Juan de Dios. Esta noticia ya había sido suministrada por Ruiz de Cortázar, figura contemporánea a las obras, citando en su libro la construcción gracias a esta donación de "otro patio claustrado, una grande pieza de enfermeria, fuente y una escalera de jaspe muy particular por su hechura con otras oficinas precisas a su mayor conveniencia y utilidad" 11 .

Andrés de la Azuela era natural de Viergol en el burgalense Valle de Mena y en su testamento declara ser acreedor de una deuda de 8.979 pesos dobles y seis reales de plata pendientes de cobrar de las que lega la mitad al convento hospital de San Juan de Dios y la otra mitad a la Obra Pía de los Niños Expósitos ${ }^{12}$. Pedro de Arriaga ${ }^{13}$, nombrado albacea testamentario, se hizo cargo de la ejecución de la última voluntad de Andrés de la Azuela que consistía, como ya hemos visto, en socorrer al convento de San Juan de Dios en el que según palabras del propio Arriaga "no cabian las correspondientes camas para la muchedumbre de pobres enfermos que ocurren a el por cuia razon estavan Incomodos y tambien sus Relix. asi por falta de Celdas como de dhas ofisinas y deseando el maior alivio de todos entre otras cosas me dejo comunicado el que edificase dha obra, la qual e echo asi de enfermerias, seldas, como de asesorias, ofisinas, campo sto., sala de profundis, segundo patio claustrado, su escalera principal, la fuente y demas obra nueva" ${ }^{14}$. La cantidad de dinero legada fue elevada y su gestión permitió financiar las obras comentadas en las que se gastaron 395.925 reales y 4 maravedíes de vellón. Pero además se entregaron a lo largo de distintos años con el fin de redimir ciertos censos, varias cantidades que en conjunto sumaron otros 17.935, 25 reales de vellón y finalmente 2.142,5 ducados de vellón para la adquisición de una casa en la calle de las Comedias Viejas (Misericordia) paredaña con el convento y que serviría para ampliar sus dependencias ${ }^{15}$. Estas cantidades entregadas obligaban al convento a celebrar una memoria anual perpetua con misa, vigilia y responso a favor del testador y a ceder, con carácter vitalicio, al, por esos años prior, Fray Gabriel Ortega, una celda grande con dos habitaciones levantada en agradecimiento por "lo mucho que le devo y me a ayudado y esforzado en el trabajo, diresion y cuidado de la obra".

10 A.H.P.C.. Protocolos de El Puerto de Santa María. Leg. 512. Escribanía 4a. 1726, fol. 110.

11 RUIZ DE CORTAZAR, Anselmo: Puerto de Santa María ilustrado y compendio Historial de sus Antigüedades (1764).Edición de Manuel Pachado Alabate y Enrique Pérez Fernández. El Puerto de Santa María, 1997, pág. 432. Sin citarlas explícitamente, Hipólito Sancho también hace mención a estas obras de reforma. SANCHO DE SOPRANIS, Hipólito: Historia del Puerto de Santa María. Desde su incorporación a los dominios cristianos en 1295 hasta el año mil ochocientos. Ensayo de una síntesis. Edición a cargo de Francisco Javier Fornell Fernández. Cádiz, 2006, pág. 232. Posteriormente este mismo autor escribió un artículo el 19 de agosto de 1957 en el periódico La Información del Lunes titulado Algunas noticias sobre Francisco de Gainzarain, maestro cantero en el que cita el documento del gasto de la testamentaría de Andrés de la Azuela. Dicho artículo aparece citado por ALONSO DE LA SIERRA, Lorenzo y Juan: Guía artística de Cádiz. Cádiz, 1987, pág. 159.

12 El testamento se realiza el 22 de octubre de 1732 y la cantidad adeuda por la compañía formada por Lorenzo y Casimiro García de Cádiz estaba reconocida por una obligación contraída en 1725 ante el escribano Juan Luis de Vergara, que se encontraba pendiente de resolución judicial del Tribunal de Consulado.A.H.P.C. Protocolos de El Puerto de Santa María. Escribanía 6a. Leg. 535. 1732, fol. 953 y ss.

13 En el censo realizado por el cabildo portuense en 1734, contemporáneo con las obras de reforma del Hospital de San Juan de Dios, figuraba Pedro de Arriaga como natural de Vizcaya, comerciante de 24 años y residente en la calle Luna en casas de Pablo Leonardo. A.M.P.S.M. Papeles Antiguos. Leg. 50-n 3, fols. 36-36v

14 A.H.P.C. Protocolos de El Puerto de Santa María. Leg. 552. 1735. Manifestación de obra y fundacion de Memoria entre D. Pedro de Arriaga y el Convento de No . Sr. San Juan de Dios. Documento anejo con desglose de gastos efectuados en la obra, fol. 264-274.

15 El protocolo de venta establece que dichas casas en la calle de las Comedias Viejas lindaban por una parte con el convento y por otra con casas de los herederos de Joseph Arestiqueta y fueron vendidas por Sebastián Ansaldo y su mujer Paula Tomasa Oneto al Convento, el cual a través de su prior, Gabriel de Ortega, pagó la cantidad estipulada recibida previamente de la testamentaría de Andrés de la Azuela, con la condición específica que dicha casa se aplicara a la ampliación de la enfermería de tal manera que cuando hubiese fondos se derribara y construyera una enfermería o se ampliara la existente . A.H.P.C. Protocolos de El Puerto de Santa María. Leg. 540. Cesión de Pedro de Arriaga al Convento de San Juan de Dios, fol. 852-853. Ídem. Venta de Sebastián de Ansaldo y su muger al Convento de San Juan de Dios. 856-859v. 
De esta manera nos situamos en 1734, año en que se inician las obras de reforma, que se extienden hasta julio del año siguiente. El presupuesto de gasto que acompaña al protocolo de fundación de la memoria anual y realización de la obra será el documento que nos permita conocer aspectos fundamentales de la intervención que generó la definitiva configuración dieciochesca del inmueble.

La reforma proyecta añadir nuevas dependencias al convento-hospital tal es el caso del granero, sala de profundis y cementerio ${ }^{16}$, y completa las existentes estructurando definitivamente la tipología conventual y hospitalaria que definirá el sentido y función del edificio. Ya hemos mencionado que en 1709 existía la iglesia, el claustro y obviamente dependencias hospitalarias. Sin embargo, no sabemos, y resulta difícil conocer, cuál era el estado real de esos espacios. La iglesia estaba plenamente construida, si bien puede pensarse que aún pendiente de elementos finales como el retablo mayor ${ }^{17}$. El claustro, por su parte, ya existía, como ha quedado demostrado a través de citas documentales, y no parece que en estos años de la reforma resultara afectado o modificado. Un claustro que en la actualidad, pese a la intervención del siglo XX en la que se cerraron los arcos con cristaleras, está bien conservado y mantiene una planta rectangular con diez arcos de medio punto rebajados de enjutas resaltadas y rosca tallada, que apoyan en otras tantas columnas de mármol blanco a través de un pequeño cimacio. Un entablamento decorado con triglifos y mútulos diferencia al segundo cuerpo. Èste articula sus muros con pilastras toscanas de fuste labrado con rosetas y balcones con las jambas y el dintel también tallados con roleos vegetales y angelotes en las claves. Dichos vanos rematan en un frontón triangular partido en cuya clave se sitúan representaciones iconográficas de bustos de santas y de la Inmaculada Concepción. El tercer cuerpo, separado por otro entablamento de menor entidad, queda conformado por pilastras toscanas lisas y vanos rectangulares. Desde el punto de vista estético, el claustro presenta una doble visión. Por un lado, la planta baja con unos referentes más clasicistas, que sigue probablemente las pautas del recién inaugurado Hospital de la Caridad, que pese a su mayor estilización, presenta rasgos formales muy similares a los concebidos para el de la Misericordia. Y por otro, el segundo cuerpo, en un orden más dieciochesco y con los vanos y pilastras tallados que resultan de un intenso contraste, acentuado en la actualidad por el blanco fondo del muro que perfila y resalta excesivamente las tallas. El tercer cuerpo, por su parte, en cantería vista, contribuye a la excesiva carga visual de este pequeño claustro que queda aún más comprimido por la presencia del zócalo corrido y las cristaleras que cierran las arcadas.

En este esquema compositivo y, atendiendo al ideario de la orden hospitalaria, resulta un elemento de interés el conjunto de referencias iconográficas femeninas que figuran en las claves de los frontones de las ventanas del primer piso del, llamémosle, claustro principal. El programa iconográfico denota los vínculos que la Orden guarda con la Inmaculada Concepción y con la práctica de la caridad

\footnotetext{
16 Entre febrero de 1738 y mayo de 1740, unos años después de iniciada la reforma, se construye el cementerio que quedó articulado en cinco partes y elevado una vara y media del suelo. Del mismo modo un depósito de cadáveres de unos 6 x 5 metros y un panteón con 18 nichos con altar adornado "con una cruz grande y un crucifijo de marfil" para enterrar a los religiosos. A.M.P.S.M. Beneficencia. Hospital de San Juan de Dios. Leg. 274-C. Libro de gastos, fol. 4-5v.

17 El retablo mayor actual fue construido entre febrero de 1738 y mayo de 1740 . Así consta en el libro de gastos del convento: "un retablo de tres cuerpos que sirve de altar mayor de muy primorosa talla y arquitectura con su sagrario interiormente dorado y la efigie de Na. Sra. De los Dolores que está en medio de dicho altar, estofada y dorada como así mismo Na. Sto. Arcángel San Rafael”. A.M.P.S.M. Benificencia. Hospital de San Juan de Dios. Leg. 274-C. Libro de gastos, fol. 4-5v. Noticia recogida citando, sin documentar, a Hipólito Sancho por HERRERA GARCÍA, Francisco J.: Aproximación a la retablística dieciochesca en El Puerto de Santa María. En La Conservación de Retablos. Catalogación, Restauración y Difusión. Serie Encuentros de Primavera en El Puerto. Editado por María Dolores Ruiz de la Canal y Mercedes García Pazos. El Puerto de Santa María, 2006, págs. 147-176

El dorado del retablo se contrató en 1759 con Bartolomé Camacho Mendoza ALONSO DE LA SIERRA, Lorenzo: Aproximación a la escultura jerezana del siglo XVIII: Francisco Camacho de Mendoza. En Atrio, nº 5.1993, págs. 225-48. Sin embargo en 1760 aún no se había concluido (A.M.P.S.M. Beneficencia. Hospital de San Juan de Dios. Leg. 274C, fol. 26v). En este mismo año fueron reparadas también en su policromía buena parte de las imágenes que contenía. No obstante, a lo largo del siglo hubo otras intervenciones previas y posteriores a ésta en el retablo mayor. Así, entre 1740 y 1744 se estofó de nuevo la imagen de San Carlos Borromeo. (Idem, fol. $10-11)$.

Igualmente fue renovada la escultura de Na. Sra. de las Angustias por el padre Fray Manuel de Ismula. Ibidem. Entre 1744 y 1747 se doraron y estofaron de nuevo las imágenes de san Miguel Arcángel y San José. (Idem, fol. 13-13v).

En este mismo período se doró el relieve de san Juan de Dios del retablo del brazo del crucero del lado del evangelio de la iglesia. (Ibidem).

Además en estos dos años se llevó a cabo la construcción de un nuevo retablo e imagen de San Rafael Arcángel que se doró entre los años 1730 y 1763. (Idem, fol. 26-35v).
} 
a través de las vidas de las santas representadas ${ }^{18}$. Téngase en cuenta que en la Basílica de San Juan de Dios iniciada en Granada en 1734 estaba bajo la advocación de la Inmaculada.

La presencia de este claustro organizaba el ámbito conventual, sin embargo, dada la ampliación, de marcada tendencia asistencial, se hacía necesaria la presencia de un nuevo claustro que regulara y estableciera orden espacial. Un claustro, que además de asumir la función utilitaria, fuera también un organizador, centralizador y distribuidor racional del espacio arquitectónico.

De esta forma y como fundamento de la gran ampliación, se inicia el segundo claustro en 1735 a raíz de la donación recibida por el ya citado Azuela.

\section{El nuevo claustro}

En la cuenta de gastos de la obra queda constancia del pago al cantero Francisco Gainzaráin de 175 pesos por la entrega de siete columnas de mármol al precio de 25 pesos cada una; así como de 210 reales por la adquisición de "cuatro piedras grandes para arcos" y otros 122 reales por "208 cartabones del patio"19. Estos datos concretos sobre la intervención en el nuevo claustro, envueltos en una extensa y detallada relación de gastos en materiales de diversa naturaleza para la obra total, no permiten hacernos una idea excesivamente precisa de cómo sería la obra del nuevo espacio. Incluso en la descripción que se hace casi dos siglos después en la Revista Portuense como consecuencia de las obras de reforma del edificio, tan sólo se menciona este segundo patio como lindero con la escalera de la entonces Escuela

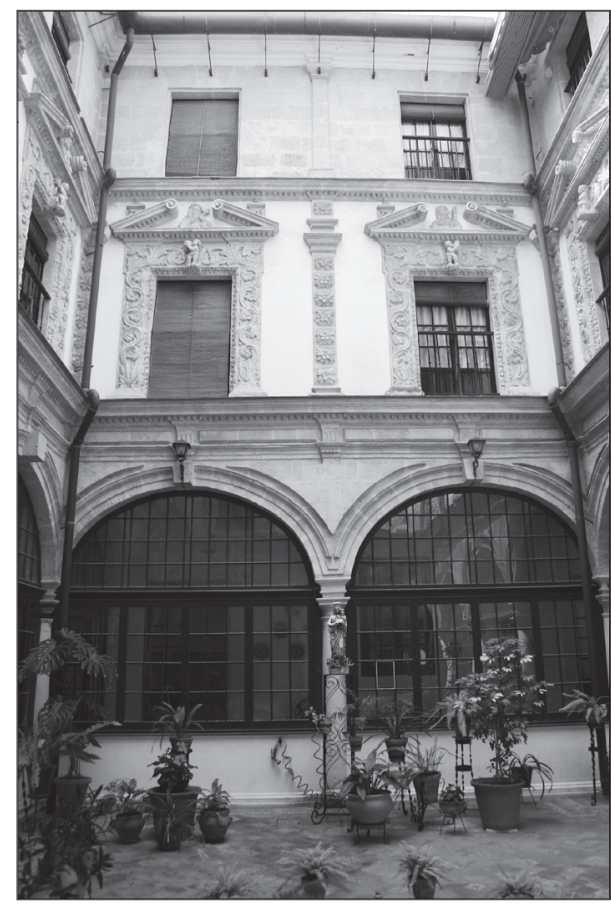

Vista del claustro principal.

\footnotetext{
18 Algunas santas, dado el estado de conservación, resultan difíciles de identificar, pero en principio se puede hablar partiendo de la Inmaculada y hacia la derecha de santa Bárbara, santa Cecilia, santa Rosa de Lima, santa Clara, santa Lucía, santa Casilda, santa Rosalía, tal vez santa Justa y santa Genoveva.
} 
de San Casiano $^{20}$. En la actualidad es un pequeño patio de recreo muy reformado, situado frente a la puerta de acceso del colegio y en el que figura una galería claustral con cuatro columnas y cuatro arcos cegados y calados por vanos. El interior del patio presenta planta rectangular con arcos de medio punto rebajados sobre muro a modo de pilares y decorados con pinjantes de gran tamaño y trazado mixtilíneo. Además muestra una segunda planta de paramentos lisos con ventanas y articulada con elevadas y desproporcionadas pilastras toscanas.

Esta intervención de carácter estructural, además de otras labores ${ }^{21}$, se complementó con otra ornamental consistente en la instalación de una fuente central que constaba de una pila de mármol por la que se pagó 1.661,5 reales de plata y se asentó sobre obra de cantería por cuanto también se especifica en la cuenta de gastos la compra de cartabones para la fuente, así como un pago de 22 pesos por un cañón de bronce para el surtidor.

En el proceso cabe suponer que se procedió, como era por otra parte habitual, a revestir de azulejería los muros. No obstante, de la cantidad de material adquirido pudiera entenderse que dicha actuación se extendió a otras zonas del inmueble ${ }^{22}$.

La generación de este nuevo espacio claustral, dotado de plantas, requería la construcción de una nueva escalera. Ésta, y con la pretensión de hacer más representativa esta parte pública del conventohospital, adquirirá una prestancia decorativa que se concentrará en la bóveda a través de su revestimiento con yeserías vinculadas con la escuela cordobesa.

La caja de la escalera, de planta rectangular, cubre con bóveda ovalada apoyada sobre pechinas y rematada por un falso lucernario con un florón de madera tallado en su interior. La decoración y articulación se realiza a través de ocho fajas radiales sin enmarcar, enlazadas por guirnaldas y formadas por volutas y acantos que arrancan del lucernario con cabezas de angelotes y animales fantásticos de forma alterna. Dichas fajas se extienden hasta la línea de imposta de la bóveda, culminando en tarjas revestidas de carnosas hojas de acanto de gran plasticidad y roleos vegetales que en las pechinas envuelven yelmos con la cruz de Santiago, figurando en dos de esas tarjas un escudo nobiliario con su correspondiente inscripción ${ }^{23}$. Una cornisa y una cenefa decorada con veneras y roleos cierran

\footnotetext{
19 Francisco Gainzaráin trabajó como maestro cantero en Sevilla en torno al año 1705. Se casó con la hija de Lorenzo Fernández Iglesias, también maestro cantero, que realizó la portada del Palacio Arzobispal de Sevilla y colaboró con el hijo de éste, su cuñado Juan Fernández Iglesias, igualmente maestro cantero. Su labor se desarrolló en Sevilla extendiéndose a El Puerto de Santa María y a Cádiz donde realizó el triunfo de San Francisco Javier. Al respecto véase HERRERA GARCÍA, Francisco José; PALOMERO PARAMO, Jesús: Fuentes para la historia del arte andaluz. Noticias de arquitectura (1700-1720). Sevilla, 1990, págs. 15-47-51-5268-69-171. HERRERA GARCÍA, Francisco José: Lorenzo Fernández Iglesia, un maestro cantero montañés en Andalucía Occidental. Atrio, Sevilla, $\mathrm{N}^{\circ}$ 0, pág. 9-28. ALONSO DE LA SIERRA FERNÁNDEZ, Juan y Lorenzo: Guía artística y monumental de Cádiz. Cádiz, 1995, pág. 133. También SANCHO DE SOPRANIS, Hipólito: Algunas noticias... Op. Cit. en el que cita la presente obra, así como la construcción de la portada de la desaparecida Casa del Marqués de la Cañada en El Puerto de Santa María. La presencia de Gainzaráin en El Puerto se relaciona con la postura y adjudicación de la obra de la fuente de la ciudad en la que participó junto al maestro de obras Francisco de Valladolid (A.M.P.S.M.. Escribanía de Cabildo. Leg. 2. 1727, fol. 23-39). Si bien su estancia en la ciudad se remonta a 1719, año en que aparece relacionado en el padrón de la ciudad figurando como maestro cantero de 45 años, viviendo son su mujer de 34 y su hija de 5 años en la calle San Sebastián en casas de Juan Cerquera (A.M.P.S.M.. Papeles Antiguos. Leg. 1650-A. Padrón de 1719) Estando en esta ciudad actúa, a través de un poder dado a Juan Fernández Iglesias, como fiador de Marcos Sancho, Joseph García y Joseph San Martín en las obras de la Fábrica de Tabacos de Sevilla en 1728 (A.H.P.C.. Protocolos de El Puerto de Santa María. Leg. 517. 1728, fols. 338-338v). Del mismo modo, unos años después estaba trabajando para el Duque de Medinaceli en la reconstrucción del muro del castillo de El Puerto de Santa María que hacía frente a la plaza de Vizcocheros y en el que se compromete a levantar "la pared de tres quartas de gruesso, seis varas de alto desde la superficie y su coronación de almenas.." (A.H.P.C.. Protocolos de El Puerto de Santa María. Leg. 540. 1733, fol. Ilegible. El protocolo se dio el 13 de agosto de 1733). Obras que fueron llevadas a cabo por cuanto el mismo año se otorgó carta de pago por la conclusión de las mismas (A.H.P.C.. Protocolos de El Puerto de Santa María. Leg. 540. 1733, fols. 244-244v.)

20 A.M.P.S.M. Leg. 3361. Revista Portuense 28/02/1924. La Escuela de San Casiano fue instalada en las dependencias del Hospital de San Juan de Dios.

21 En la relación de gastos se mencionan pagos de 761 reales por la "hechura de diferentes rexas y balcones", de 1.610 reales por la "hechura de 19 rejas y un guardapolvo", así como 169 por pintar las "rexas y balcones".

22 El pago realizado era de 12.264 reales y en él se incluía además del costo de la azulejería, el corte de 11.020 azulejos y la adquisición de 26 canales de barro. Por el número de losetas adquiridas pudiera pensarse que esta fórmula decorativa se extendiese incluso a la iglesia. Los que ahora existen en ella son de la reforma del primer tercio del siglo XX.

23 "SOI DELA CASA SOLA DE ARIAGA". La inscripción y en consecuencia la presencia del escudo que vincula este espacio con la familia Arriaga resulta, en principio y con la información obtenida hasta ahora, contradictoria con la financiación de la obra por parte de Andrés de la Azuela
} 


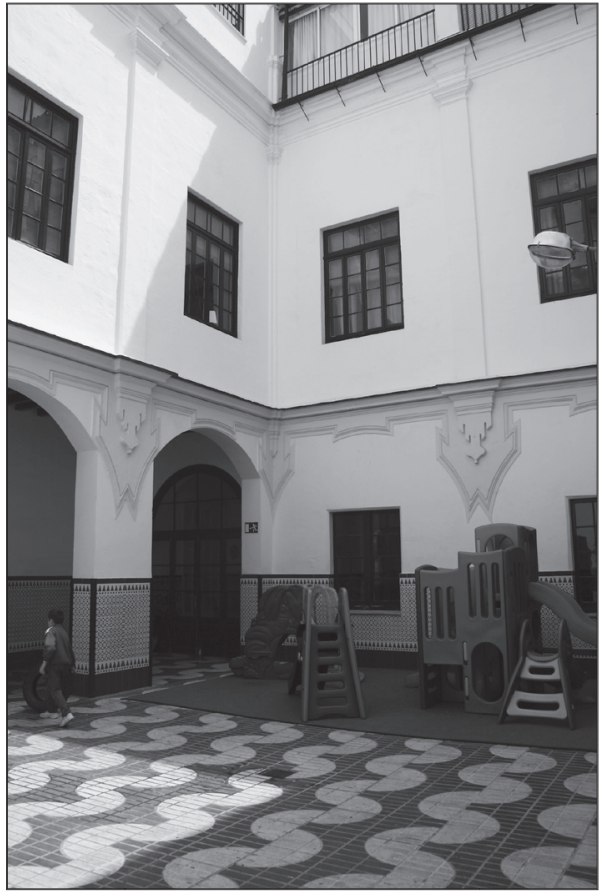

Vista del claustro nuevo.

la composición. Se desconoce al autor de las yeserías pero su diseño, cuya decoración en un afán barroco, aún contenido, desborda tímidamente el marco arquitectónico, la vincula con formas barrocas cordobesas $^{24}$ y su presencia debió ser aún más notable con la policromía que, al menos en determinadas zonas, las revistió originalmente y de la que aún puede observarse restos ${ }^{25}$.

Para la escalera del nuevo claustro se adquirió, al ya citado maestro cantero Gainzaráin, una baranda de mármol por la que se pagó 300 pesos, más otros 270 por 30 escalones, también de mármol, y otros 60 pesos por lo que denomina "guarnizión de la escalera". A estos gastos hubo que añadir la compra de 5 pernos y 10 pesos por su colocación en la escalera. Dicha escalera fue trasladada en el año $1769^{26}$ a su actual emplazamiento del claustro conventual y se compone de tres tramos, dispuestos los dos primeros en sentido inverso y el tercero transversal. Consta de escalones de mármol y de tres fragmentos de una espléndida baranda, cada uno de ellos articulado por pilaretes extremos rematados por bolas sobre un soporte muy moldurado. Entre los citados pilaretes se disponen balaustres asentados sobre basas, así como un ancho pilar central cajeado, discurriendo sobre ellos el pasamanos de sección circular con la base rebajada.

\footnotetext{
24 Téngase en cuenta que durante la primera mitad del siglo XVIII se llevaron a cabo en el marco geográfico cordobés reformas en los hospitales de la Orden, siendo las yeserías uno de los elementos ornamentales más significativos de los diversos espacios arquitectónicos construidos o modificados. De este modo no resultaría extraño la presencia de algún tallista de esa zona en las obras de reforma de este hospital-convento de San Juan de Dios. Al respecto véase RIVAS CARMONA, Jesús: Arquitectura barroca cordobesa. Córdoba, 1982, págs. 204-220.

25 Se sabe que de abril a mayo de 1735 se efectuaron diversos pagos a cuenta de la decoración de la escalera. Así se abonaron 16 pesos por el florón, 34 por el dorado y pintado y 54 reales por el vástago para colocarlo. En ese mismo mes se abonaron 4.080 reales "a los tallistas por el entallado de la bobeda de la escalera" y 16 pesos "al pintor por los escudos de armas que pinto en la bóveda de dcha escalera".

26 A.M.P.S.M. Beneficencia. Hospital de San Juan de Dios. Leg. 274-C. Libro de gastos. 1769, s/f.
} 


\section{La portada de la iglesia}

La última parte de la reforma que se llevó a cabo se refiere a la portada de la iglesia. No se tiene constancia del momento exacto de su construcción, pero es cierto que sus formas se alinean con la estética seiscentista y que por tanto cabría incluirla en el período constructivo que se extiende entre 1653 y 1671. En cualquier caso, ya se encontraba levantada en estos dos años que dura la reforma dieciochesca. La intervención se concentró en dotarla de referentes iconográficos de la Orden para transformarla en hito señalizador de la presencia Hospitalaria en las labores asistenciales de la ciudad. La modificación consistió en añadirle los tres escudos que en la actualidad posee, esto es, las dos tarjas que se sitúan en las pilastras laterales y el escudo coronado que domina el dintel de la puerta y que fue realizado por un, por el momento, anónimo escultor de Cádiz. Los tres elementos mostraban el anagrama de la Orden de San Juan de Dios, la cruz sobre la granada abierta. Pero además se añadieron tres cruces, una de las cuales estaría situada en la hornacina hoy ocupada por una imagen de la Virgen con el Niño. Dichas cruces estaban doradas por lo cual podemos pensar en el uso de color para su concepción visual. La portada sufrió una importante modificación con esta reforma. A sus rasgos manieristas tardíos se incorporan elementos ornamentales que alteran su diseño primitivo con la idea de acentuar la función identificadora del inmueble ${ }^{27}$. A esta reforma, que modificó la composición original, habría que sumarle la nueva construcción del último cuerpo del campanario que, siendo afectado por el terremoto de 1755 , fue edificado en $1765^{28}$.

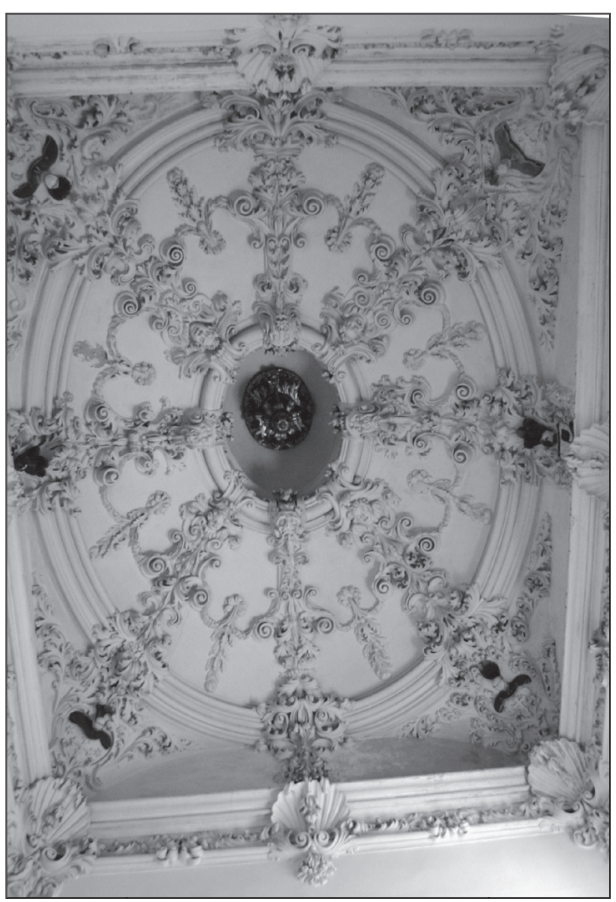

Boveda de la escalera.

27 En las cuentas de la obra se pagan 37,22 reales por 1 piedra martelilla para las granadas de la portada; 67,25 por dorar las cruces de la portada; 90 pesos a un tallista de Cádiz por el escudo de armas de mármol de la portada; 67 reales por tres cruces para la portada. 14 pesos al cantero Francisco Gainzaráin por 1 piedra para el escudo de armas y 263,27 reales por cuatro garras de bronce para el escudo de armas. 
La relación de gastos de la obra detalla con precisión cada uno de los pagos que se hicieron, pero, a excepción de los citados, el resto se refieren a la adquisición de materiales para la construcción y utensilios, así como jornales para los trabajadores ${ }^{29}$. Desgraciadamente no es detallista con los autores de este amplio proceso. Tan sólo figura Francisco Gainzaráin, maestro cantero, y Diego de las Casas como posible diseñador de azulejos ${ }^{30}$. No obstante, el prior del convento Fray Gabriel Ortega consta en los textos como una figura a destacar en el "cuidado y dirección de la obra" y tal vez su presencia fuera un punto importante en la guía y proceso de reformas habidas en el convento hospital de San Juan de Dios ${ }^{31}$. Aún así, hay que pensar en la actuación de un arquitecto que elaborara y ejecutara el proyecto. Durante estos años también se estaba levantado el convento de San Miguel Arcángel en la calle Larga, dirigido por Andrés Alarcón Panyagua, si bien, al parecer, bajo las trazas del arquitecto Diego Antonio Díaz. En estas mismas fechas además se encontraban en activo una serie de maestros de obras que intervinieron en la ciudad durante este segundo tercio del siglo XVIII. Es el caso de Miguel de Santiago y Francisco de Valladolid. Éste último, alcanzó cierto prestigio trabajando para Juan Carlos de Rivas Ramírez de Arellano en la construcción de su residencia en la calle Luna ${ }^{32}$ y además, como ya hemos visto, había mantenido contactos profesionales en años anteriores con el cantero Francisco Gainzaráin.

De este modo, queda configurada la disposición arquitectónica definitiva del convento-hospital de San Juan de Dios de El Puerto de Santa María. A lo largo de los años, y así consta en la documentación,

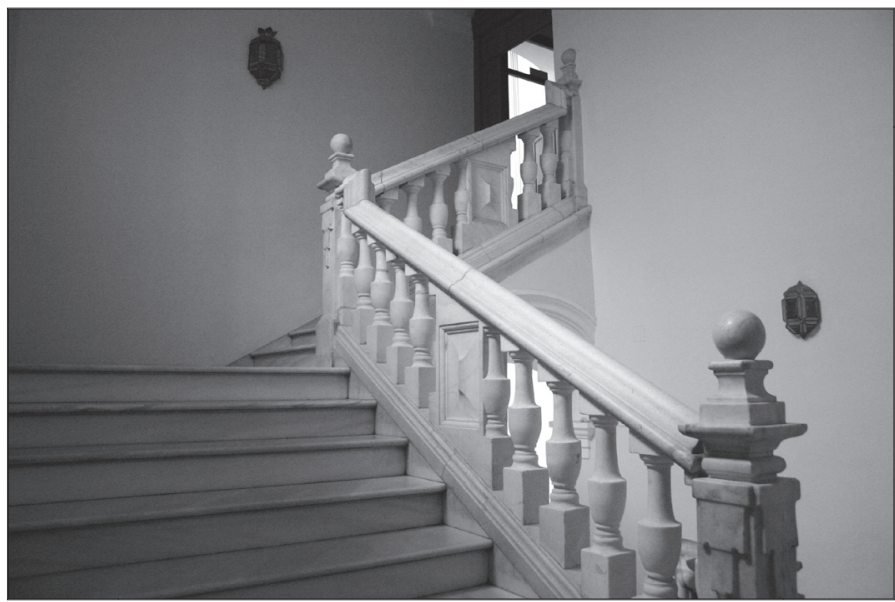

Escalera claustral.

\footnotetext{
28 A.M.P.S.M. Beneficencia. Hospital de San Juan de Dios. Leg. 274-B. Libro de gastos, fol. 290v. El coste de la obra fue de 1.495 reales de vellón.

${ }_{29}$ Los principales gastos se efectuaron en materiales para la construcción. Así se gastaron 1.636 quintales de yeso; 84.566 ladrillos de Málaga; 97.900 ladrillos de Sevilla; 5.000 ladrillos de Jerez; 1.293 carretadas de piedra de labor; 932 carretadas de cantillo. 310 carretadas de ripio; 32.450 tejas de Moguel y 95.484 reales en jornales para peones y maestros de la obra.

30 No se conocen datos de la existencia de Diego de las Casas como azulejero, sin embargo en la capilla de Jesús Nazareno de la parroquia de $\mathrm{N}^{\mathrm{a}}$. Sra. de la $\mathrm{O}$ de Rota figura un panel de azulejería firmado por Joseph de las Casas de Triana en 1755 , que bien pudiera guardar relación familiar y de taller con Diego de las Casas.

PLEGUEZUELO, Alfonso: Una aproximación al estudio de los zócalos de azulejos sevillanos en el siglo XVIII. En Homenaje al Prof. Dr. Hernández Díaz, Sevilla, 1982. T. I., Págs. 575-585. También citado por ALONSO DE LA SIERRA, Juan y otros: Guía artística de Cádiz y su provincia. Diputación de Cádiz y Fundación José Manuel Lara. Sevilla, 2005. Pág. 91.

31 En 1737 donan al Padre Fray Gabriel Ortega un esclavo comprado en 1722 en Portovelo, llamado Francisco Diego Anastasio que es devuelto al poco tiempo. AH.P.C.. Protocolos de El Puerto de Santa María. Leg. 560. 1737, fols. 670 y 854.

32 Al respecto véase BARROS CANEDA, José Ramón: Arquitectura doméstica en El Puerto de Santa María. La casa de los Rivas. En Laboratorio de Arte, nº 9, 1996, Sevilla, págs. 345-357
} 
se hicieron innumerables obras de reparación y mantenimiento como por ejemplo el citado cambio de la escalera del nuevo claustro al principal y la construcción de bóvedas nuevas en un lienzo del nuevo claustro en el año $1769^{33}$. Sin embargo, la estructura y disposición arquitectónica quedaba definitivamente fijada hasta que en 1923, a raíz de su cesión a las Esclavas del Sagrado Corazón ${ }^{34}$, se llevó a cabo otro proceso de reforma que afectó esencialmente a la fachada de la calle Misericordia en la que se ejecutó todo un proceso de reordenación de muros y huecos, estableciéndose una ordenada continuidad visual que terminaba por fijar la presencia del inmueble en el contexto urbano.

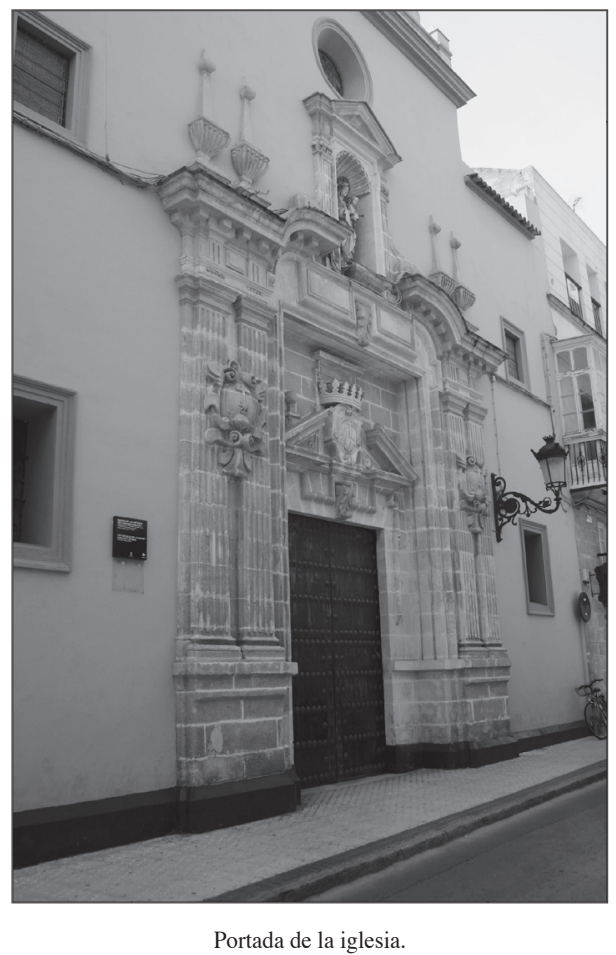

33 A.M.P.S.M. Beneficencia. Hospital de San Juan de Dios. Leg. 274-B, fols. 51-51v.

34 LOZANO CID, Olga; GARCÍA PAZOS, Mercedes: Guía Histórico-Artística de El Puerto de Santa María. Cádiz, 1983, pags. $27-28$. 